
Not for reproduction, distribution or commercial use.

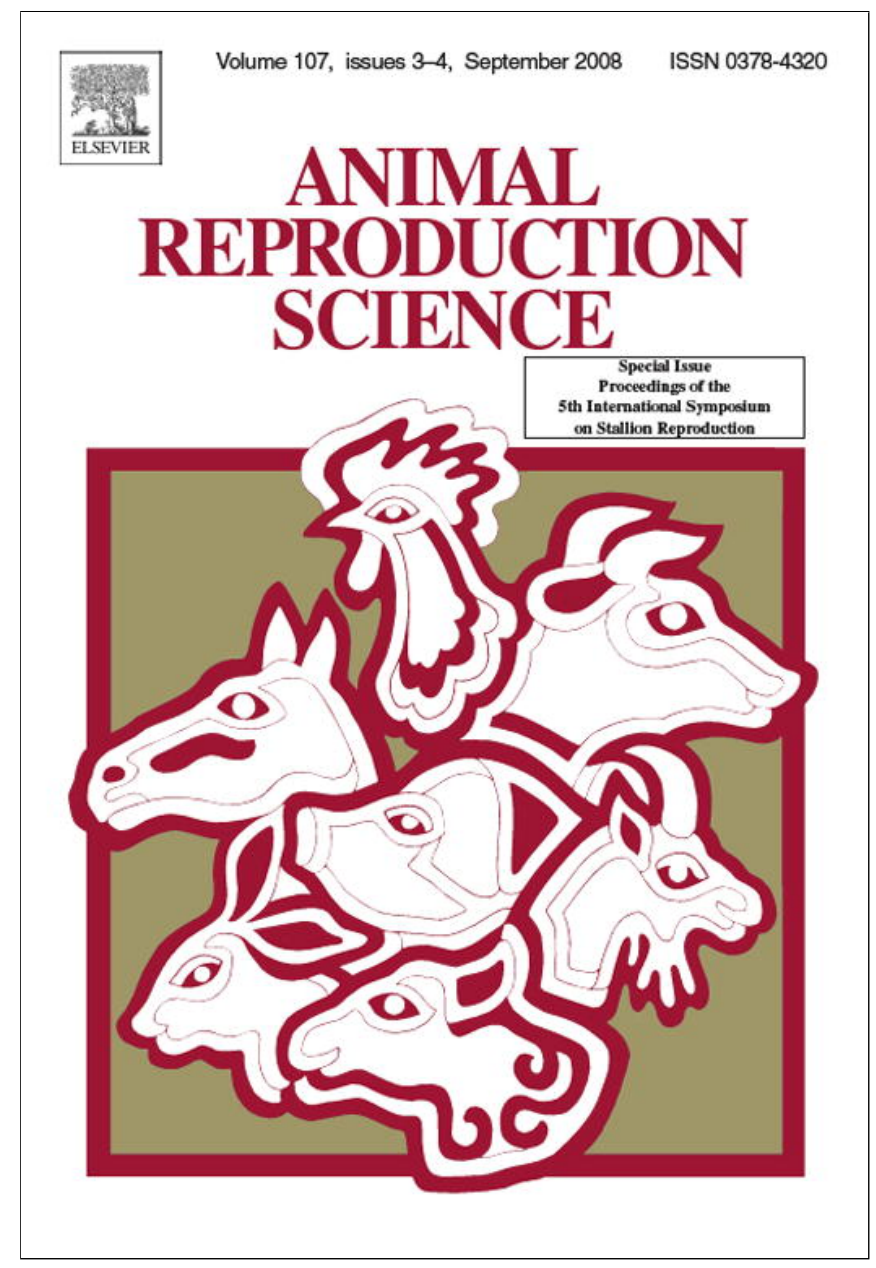

This article appeared in a journal published by Elsevier. The attached copy is furnished to the author for internal non-commercial research and education use, including for instruction at the authors institution and sharing with colleagues.

Other uses, including reproduction and distribution, or selling or licensing copies, or posting to personal, institutional or third party websites are prohibited.

In most cases authors are permitted to post their version of the article (e.g. in Word or Tex form) to their personal website or institutional repository. Authors requiring further information regarding Elsevier's archiving and manuscript policies are encouraged to visit:

http://www.elsevier.com/copyright 


\title{
The roles of the epididymis and prostasomes in the attainment of fertilizing capacity by stallion sperm ${ }^{\text {i⿱ }}$
}

\author{
E. Sostaric ${ }^{\mathrm{a}, *}$, M. Aalberts ${ }^{\mathrm{a}}$, B.M. Gadella ${ }^{\text {b,c }}$, T.A.E. Stout ${ }^{\mathrm{a}, \mathrm{d}}$ \\ a Department of Equine Sciences, Faculty of Veterinary Medicine, Utrecht University, \\ P.O. Box 80.156, NL-3508 TD Utrecht, \\ The Netherlands \\ b Department of Biochemistry and Cell Biology, Faculty \\ of Veterinary Medicine, Utrecht University, P.O. Box 80.176, \\ NL-3508 TD Utrecht, The Netherlands \\ ${ }^{\mathrm{c}}$ Department of Farm Animal Health, Faculty of Veterinary Medicine, \\ Utrecht University, Yalelaan 7, 3584 CL Utrecht, \\ The Netherlands \\ ${ }^{\mathrm{d}}$ Department of Production Animal Studies, Faculty of Veterinary Science, \\ University of Pretoria, South Africa
}

Available online 29 April 2008

\begin{abstract}
The epididymis is a long, tightly coiled tube within the lumen of which sperm matures. Sperm maturation involves morphological and biochemical changes in the sperm plasma membrane in response to epididymal secretions and their various proteins. Some of these proteins become outer membrane components while others become integral membrane proteins; transfer of some proteins to the sperm plasma membrane may be mediated by epididymosomes. Nevertheless, the molecular pathways by which spermatozoa acquire fertilizing capacity during their transit through the epididymis remain ambiguous. In a recent study of stallion epididymal sperm, we found that sperm harvested from different parts of the epididymis (caput, corpus and cauda) had a varying, but generally poor, ability to undergo the acrosome reaction in vitro. At ejaculation, however, sperm mix with seminal plasma which contains various components, including the small membranous vesicles known as prostasomes, that may enable the sperm to undergo physiological activation. Seminal plasma components may have a 'washing' effect and help to remove 'de-capacitation' factors that coat the sperm during storage in the cauda epididymis; alternatively seminal plasma and prostasomes may contain factors that more directly promote sperm activation. This article reviews current information
\end{abstract}

\footnotetext{
败 This paper is part of the Special issue entitled "Proceedings of the 5th International Symposium on Stallion Reproduction", Guest edited by Terttu Katila.

* Corresponding author. Tel.: +31 30 2539775; fax: +31 302531054.

E-mail address: e.sostaric@uu.nl (E. Sostaric).
} 
on the roles of epididymal and accessory gland fluids on the acquisition of fertilizing capacity by stallion sperm.

(C) 2008 Elsevier B.V. All rights reserved.

Keywords: Stallion; Epididymis; Ejaculation; Sperm capacitation

\section{Introduction}

During their passage from the testis to the site of fertilization in the oviduct, mammalian spermatozoa encounter a wide range of fluids of different origins and composition (e.g. testicular and epididymal fluids, seminal plasma and oviductal fluid). These fluids have a major influence on post-testicular development and induce a range of temporally controlled maturational changes that allow sperm to develop fertilizing capacity, and culminate in the induction of capacitation. As a result of these changes, spermatozoa are transformed from immotile cells incapable of fertilization to vigorously active cells capable of binding to and fusing with an oocyte.

In mammals, the epididymis has numerous inter-related functions including reabsorption of the fluid secreted by the seminiferous tubules, and the maturation and storage of sperm (Jones, 2004). Studies on the role of the epididymis in sperm maturation have focused on the secretory activity of the epithelial cells lining the duct, the composition of the luminal fluid and the influence of this fluid, or its components, on immature sperm.

The majority of proteins entering the epididymis from the rete testis are reabsorbed in the initial segment of the caput epididymis. As a result, most proteins found in epididymal fluid are secretory products of the epididymal epithelium (Gatti et al., 2004). During epididymal transit, spermatozoa acquire new proteins, some of which are coating proteins that can be removed by washing with isotonic or hypertonic solutions, while others are incorporated as integral membrane proteins; this latter group includes the glycosylphosphatidylinositol (GPI)-anchored proteins, the transfer of which to the sperm plasma membrane is thought to be mediated by epididymosomes.

Maturation of sperm during their transit through the epididymis can be evaluated by assessing the progress towards the expected endpoints, namely the acquisition of motility and the ability to recognise, bind to, and penetrate the zona pellucida and fuse with an oocyte. In most species, spermatozoa attain their full fertilizing potential in the proximal cauda epididymis (Dacheux and Paquignon, 1980). In horses, however, this does not seem to be the case. Although the first pregnancy reported following the use of frozen-thawed stallion sperm was achieved using epididymal sperm (Barker and Gandier, 1957), subsequent studies have suggested that the fertility of stallion epididymal spermatozoa is significantly less than that of ejaculated sperm (Morris et al., 2000); moreover, any deficiencies cannot be overcome by simply depositing the sperm hysteroscopically closer to the site of fertilization (Morris, 2004). This is disappointing because there is considerable current interest in preserving sperm from the cauda epididymis of stallions that either die suddenly or are electively castrated, with the intention of using the sperm subsequently for routine artificial insemination.

This review focuses on the major sequential modifications of sperm during their transit through the epididymis, and concentrates on the role of epididymal proteins in maturation and the acquisition of fertilizing capacity by stallion epididymal sperm. 


\section{Structure of the epididymal duct}

Embryologically, the epididymis is derived from the tissue that formed in some primitive animals the mesonephros, a primitive kidney. Anatomically, it is a tightly coiled tube that connects the efferent ducts that exit the rear of a testicle to the vas deferens. In the stallion, the epididymis has a total length of approximately $70 \mathrm{~m}$ (Nickel et al., 1979) and, as in several other mammalian species, it can be divided into a number of anatomically distinct segments or regions, i.e. the initial segment, caput (head), corpus (body), cauda (tail) and the vas deferens; the anatomical divisions do not, however, necessarily relate to function. Along its entire length, the epididymal lumen is lined by a pseudostratified epithelium composed of principal and basal cells, while other cells such as apical, narrow, clear and halo cells (intra-epithelial lymphocytes) are present in a segmentspecific manner. Together, the luminal epithelial cells perform several important roles necessary for epididymal function (França et al., 2005), including protein secretion and absorption (principal cells), endocytosis (clear cells), secretory activities responsible for acidifying the luminal fluid (clear cells and narrow cells), immune defence, phagocytosis and production of antioxidants (basal cells). In fact, the majority of epithelial cells (85\%) are tall columnar principal cells characterized by structures associated with absorption, such as prominent stereo-cilia on their apical surface and vesicles and lysosomes within the cytoplasm, and by structures characteristic of protein secretion, such as rough endoplasmic reticulum and a large Golgi complex. While the principal cells show conspicuous morpho-functional differences in different regions of the epididymis, they uniformly form tight junctions in their apical region that are largely responsible for creating an epididymal duct barrier. The combination of this physical barrier, the multiple functions of the cells lining the epithelium, and the changes in cell type and functions along the length of the duct results in a highly specialized epididymal environment for sperm transport, maturation and storage.

Although the length of the epididymis varies between species (Jones and Glover, 1975), the mean duration of epididymal sperm transit is surprisingly constant at around 9-11 days. In stallions, epididymal transit time has been reported to vary between 5 and 14 days (França et al., 2005). Movement of spermatozoa through the epididymis is primarily due to continuous peristaltic contractions of smooth muscles in the wall of the caput and corpus epididymis. In the cauda, the epididymal duct smooth muscles are generally quiescent, unless stimulated to contract.

The function of the caput and corpus regions is considered to be sperm maturation per se, whereas the cauda region is thought to be primarily involved in sperm storage prior to ejaculation. In the cauda, the specific luminal environment allows spermatozoa to survive for several weeks (Moore, 1995), primarily by maintaining metabolic quiescence and preventing premature sperm activation. During the storage period, the cauda epididymides accumulate sperm to ensure that a 'sufficient' number is available at the time of ejaculation. The volume of the cauda epididymis, therefore, broadly reflects the sperm storage capacity of the male tract. In bulls and stallions, the number of stored sperm is roughly sufficient for 10 ejaculates (Sullivan et al., 2007).

Epididymal function is regulated by androgens, such as dihydrotestosterone and, in the stallion, also probably by estrogens. In stallions, androgen receptors are distributed throughout the reproductive tract (in the testis, epididymis, and prostate: Bilinska et al., 2005), whereas estrogen receptor distribution is both age and tissue/segment dependent (Parlevliet et al., 2006). Dihydrotestosterone may be produced locally within the epididymis because the principal cells, particularly in the initial segment of the epididymis, contain $5 \alpha$-reductase (Robaire and Viger, 1995). However, luminal fluid reabsorption in the efferent ductules and in the caput region of the epididymis appears to be regulated principally by estrogens (Hess et al., 1997). Although epididymal function is predominantly regulated by testicular steroid hormones, it is also affected by 
scrotal temperature, and it has recently been suggested that the sperm themselves may influence epididymal function (Reyes-Moreno et al., 2008).

\section{Maturation of spermatozoa within the epididymis}

\subsection{Epidiymal function and sperm maturation}

In most vertebrates with internal fertilization, the epididymis is critical for post-testicular maturation and storage of sperm, at least in part because of the slow rate of spermatogenesis (Jones, 1998a). Although very few aspects of epididymal function have been studied in the stallion, the combination of these few studies and data from other species does allow us to propose a basic framework for how sperm maturation is modulated during epididymal transit. Spermatozoa formed during spermatogenesis and spermiogenesis in the testis are quiescent and, therefore, play no active role in their own transport through the epididymis. And while the secretory output of the testis is considerable, most of the fluid is reabsorbed in the efferent duct, the initial segment and proximal caput epididymides, in which passive fluid reabsorption is augmented by active ion exchange across the apical membrane of the epididymal cells (Moore, 1995).

Fully developed spermatozoa also collect in the initial segment of the epididymis, having made their way via the rete testis and efferent duct. These spermatozoa are either immotile or only weakly motile and are not yet capable of fertilizing an oocyte. The acquisition of fertilizing capacity during epididymal transit is the defining process of sperm maturation, where fertilizing capacity refers to the ability to fertilize a physiologically normal and structurally intact oocyte, either in vivo or in vitro. In general, it is not until they reach the proximal cauda epididymides that the majority of sperm attain their full fertilizing potential (Yanagimachi, 1994). Sperm maturation includes many changes in physiological properties such as the acquisition of forward motility, and the ability to recognise and bind to the zona pellucida and fuse with the plasma membrane of an oocyte.

A number of studies indicate that changes in both the structural and macromolecular composition of the sperm plasma membrane occur during epididymal maturation. The major visible change in the sperm is the shedding of the cytoplasmatic droplet. Sperm in the cauda epididymis still possess the droplet of residual cytoplasm that remains after the reshaping of the cell during spermiogenesis. In most species, the droplet moves distally along the flagellum during epididymal passage and is shed prior to or during ejaculation. Ultrastructural investigations have also revealed that the appearance and topographical configuration of the sperm plasma membrane are altered during epididymal transit (Bedford, 1965; Bedford and Nicander, 1971). This typically involves a reduction in size and a change in shape of the apical segment, changes in the appearance of the acrosomal contents (Olson et al., 2003), and changes in the density and distribution of membrane particles (López et al., 2007). In addition, the acrosome undergoes structural remodelling during which several proteins undergo post-translational processing and compartmentalization in a stage-specific fashion (Yoshinaga and Toshimori, 2003).

Many sperm biochemical characteristics are also modified during epididymal transit. Major modifications include changes in the plasma membrane composition of glycoproteins and sterols (Retamal et al., 2000), extensive cross-linking of nuclear protamines by disulphide bonds (Dias et al., 2006), an increase in total surface negative charge, relocation of surface antigens, and addition, elimination or modification of surface proteins (Sullivan et al., 2005). The maturational changes in plasma membrane phospholipid composition include a selective and progressive loss of phospholipids during epididymal transit that results in an elevated proportion of cholesterol (Jones, 
1998b). The elevated cholesterol content combined with active maintenance of an asymmetric phospholipid distribution stabilises the membrane of the mature sperm for storage in the cauda epididymis (Saether et al., 2003). Membrane alterations during epididymal maturation are, however, not limited to the plasma membrane of the sperm head. Adsorption and/or integration of several glycoproteins and peptides are also observed in the plasma membrane of the tail (Yanagimachi, 1994).

\subsection{Motility of epididymal spermatozoa}

Sperm acquire the ability to become motile during epididymal maturation, and it is thought that phosphorylation and de-phosphorylation events in sperm flagella proteins play a role in these motility changes (Tash and Bracho, 1994). The changes are regulated by intracellular mediators such as cyclic AMP, calcium and $\mathrm{pH}$, derived from the epididymal environment. Sperm structures like the outer dense fibres of the flagellum are stabilised by disulphide linkages which result from phosphorylation events triggered by the oxidation of thiol (Seligman et al., 2004). Protein phosphorylation is the net result of the actions of protein kinases and phosphatases, and immotile sperm in the caput epididymis have significantly greater protein phosphatase activity than motile sperm in the cauda epididymis. For example, the protein phosphatase isoform, PPl $\gamma 2$ (PP1 $\gamma$ ), is enriched in spermatozoa and testis, but its catalytic activity, phosphorylation and binding to regulatory proteins all change during epididymal maturation. Moreover, because decreased PP1 $\gamma 2$ enzyme activity is associated with increased motility, PP1 12 is thought to be a key protein for regulating sperm motility (Vijayaraghavan et al., 2007). Indeed, targeted disruption of the PP1 $\gamma$ gene in mice results in male sterility characterized by sperm tail malformation (Chakrabarti et al., 2007).

\section{Composition of epididymal fluid}

Within the epididymis, sperm encounter an environment that changes progressively in composition along the length of the duct. Moreover, regional specificity of epididymal fluid composition is maintained by a combination of active secretion and reabsorption combined with restricted exchange between the luminal compartment and blood plasma, as a result of the tight junctions between the epithelial principal cells (Dacheux et al., 2003).

\subsection{Proteins in epididymal fluid}

The sperm plasma membrane undergoes profound changes during epididymal transit, both in protein composition and localization (Jones and Glover, 1975; Jones et al., 2007). While spermatogenesis in the testis is under genomic regulation by the gamete, after the cell reaches the elongated spermatid stage, the DNA begins to condense such that DNA transcription slows and then stops. As a result, sperm leaving the testes are likely to have very limited biosynthetic capacity, such that during subsequent differentiation stages in the epididymis, sperm maturation is primarily regulated by interaction with the epididymal fluids (Dacheux et al., 2003).

Because almost all of the proteins that enter the epididymis in testicular fluid are reabsorbed in the initial segment, the proteins found in epididymal fluid are almost entirely a result of epididymal epithelial cell secretory activity. Moreover, proteomic analysis of epididymal fluid proteins collected by microperfusion has demonstrated that the epididymis has great secretory activity (Dacheux et al., 2003). Indeed, it has been estimated that several hundred proteins are secreted 
into the epididymal lumen, and initial proteomic analysis of stallion epididymal fluid yielded 326 peptides corresponding to 117 proteins (Fouchécourt et al., 2000). Most of these proteins are secreted in the caput region, which accounts for around $73 \%$ of total epididymal secretion in the stallion. Secretory activity decreases markedly in the cauda epididymis. Interestingly, in all species studied to date, a significant proportion of total secreted proteins is accounted for by a relatively small number of proteins. In the stallion, $92 \%$ of total epididymal protein secretion takes the form of 18 proteins, these include; lactoferrin (41\%), clusterin $(25 \%)$, procathepsin D, cholesterol transfer protein, glutathione peroxidise, beta- $N$-acetyl-hexosaminidase and prostaglandin D2 synthase (Dacheux et al., 2003). It has been suggested that the various epididymal proteins fulfil different roles, with some directly modifying the sperm membrane surface or composition and others contributing to the preservation of sperm integrity. Epididymal proteins may alter the characteristics of the sperm plasma membrane either via transport/binding functions, e.g. clusterin and cholesterol binding protein which bind hydrophobic compounds, or as a result of enzymatic activity, e.g. glycosidases, glycosyltransferases, proteases and protease inhibitors (Dacheux et al., 2003).

\subsection{Epididymosomes and their proteins}

The proteins that spermatozoa adsorb during their transit through the epididymis are classically referred to as 'coating proteins'. Most coating proteins act as principal membrane components and can be removed from the sperm surface using isotonic or hypertonic solutions. However, some proteins behave like integral membrane proteins; many of this latter category are glycosyl phosphatidylinositol (GPI)-anchored to the sperm plasma membrane, suggesting that the secreted epididymal proteins are transferred to the sperm by an unusual mechanism (Sullivan et al., 2007). Frenette and Sullivan (2001) proposed that the transfer of epididymal proteins to sub-cellular compartments of the sperm is mediated by small membranous vesicles, known as epididymosomes. Epididymosomes are electron dense vesicles secreted in an apocrine fashion and ranging between 50 and $500 \mathrm{~nm}$ in diameter. The proteins associated to epididymosomes are not processed through the endoplasmic reticulum and Golgi apparatus and are characterized by unusual glycosylation patterns. In addition, it is thought that these proteins lack a signal peptide at their $\mathrm{N}$-terminal (Sullivan et al., 2005).

Epididymosomes are rich in cholesterol, with cholesterol:phospholipid ratios as high as 2, and have sphingomyelin as their major phospholipid (Rejraji et al., 2006). Epididymosomes contain lipid rafts, i.e. cholesterol and phospholipid-enriched microdomains (Sullivan et al., 2007). These microdomains contain GPI-anchored and transmembrane proteins, as well as signalling molecules such as protein tyrosine kinases, and may serve as a platform for transferring the proteins from the epididymal epithelium to a maturing sperm (Sullivan et al., 2005). Epididymosomes originate from the various regions of the epididymis and have corresponding differences in protein composition; this is reflected in the way they interact with, and the proteins they transfer to, sperm (Frenette et al., 2006). To date, however, very few epididymosome-associated proteins have been identified, and the precise functions of these exosomes, therefore, remain obscure.

One of the first proteins shown to be synthesized and secreted by the epididymal epithelium and also associated with sperm maturation was P26h in the hamster (Robitaille et al., 1991). The $\mathrm{P} 26 \mathrm{~h}$ is involved in sperm-oocyte binding and that its presence on the sperm is an absolute prerequisite for fertilization (Bérubé and Sullivan, 1994). Moreover, P26h is found in epididymosomes and becomes GPI-anchored to the sperm surface of the acrosomal region during epididymal transit, via an as yet unknown mechanism (Sullivan et al., 2007). While homologous proteins 
have subsequently been described in man (P34H; Boué et al., 1996), cattle (P25b; Parent et al., 1999) and monkeys (P31m; Lamontagne et al., 2001), it now appears that P26h mRNA and protein are present in relatively large amounts in the testes of sexually mature hamsters whereas the P26h mRNA in the epididymis is much less (Gaudreault et al., 1999). The cellular origin of the P26h on the acrosome of sperm in the cauda epididymis remains, therefore, to be confirmed.

Another protein found in epididymosomes is HE5, which is among the few epididymal secretory products that has been cloned and shown to interact with maturing sperm in the epididymal lumen. With regard to cDNA sequence, HE5 is identical to the lymphocyte protein CD52; it is highly glycosylated and is the principal surface glycoprotein on sperm in the corpus and cauda epididymis (Kirchhoff, 1996). HE5 transcripts are present in the corpus and cauda epididymis and the vas deferens, but not the testis (Krull et al., 1993). In mature sperm, HE5 possesses only 12 amino acids which are linked via the $\mathrm{C}$ terminus to a GPI-anchor inserted into the sperm plasma membrane (Yeung et al., 2001). HE5 protein is thought to be associated with human immunological infertility (Sullivan et al., 2005).

Type 5 glutathione peroxidase (GPX5) is a protein secreted by the caput epididymis in an epididymosome-associated form (Sullivan et al., 2007) and is thought to be involved in protecting epididymal sperm against oxidative stress. Similarly, SPAM1 (PH-20) is a glycoprotein synthesized by the principal cells (Zhang et al., 2004) that associates with epididymosomes (Sullivan et al., 2007). PH-20 is located on the sperm surface and in the acrosome, where it is bound to the inner acrosomal membrane. PH-20 is a multifunctional protein which can serve as a hyaluronidase, a receptor for HA-induced cell signaling, and a receptor for zona pellucida (Cherr et al., 2001).

Enzymes of the polyol pathway, including aldose reductase and sorbitol dehydrogenase, have been identified in epididymosomes (Frenette et al., 2004) and appear to be involved in a mechanism for modulating sperm motility during epididymal transit.

Macrophage migration inhibitory factor (MIF) is a protein found in rat (Eickhoff et al., 2004), human (Frenette et al., 2005) and bovine (Eickhoff et al., 2006) epididymis and epididymal sperm. MIF has been localized within apical protrusions of epithelial cells, in epididymosomes and associated with sperm in the epididymal lumen, thereby supporting the hypothesis of apocrine secretion mediated protein transfer via epididymosomes (Eickhoff et al., 2006). Besides being a classical cytokine, MIF is capable of sustaining various other functions, depending on its subcellular or tissue distribution (Eickhoff et al., 2006). In the male rat, MIF plays a role during posttesticular sperm maturation and the acquisition of fertilizing ability by supporting the elimination of zinc from zinc-mercaptide complexes and by influencing the redox state of protein-bound sulphhydryl groups (Eickhoff et al., 2004). MIF is present along the entire epididymis with greater amounts in the caput.

In short, while proteomic studies have identified a number of proteins in epididymal fluid these represent only a small proportion of the total; a large number have still to be identified.

\section{Fertilizing ability of stallion epididymal spermatozoa}

Sperm from the proximal segment of the epididymis are unable to fertilize oocytes in vivo or in vitro (Yanagimachi, 1994). In the majority of species studied, these sperm are immotile and unable to either 'recognise' the zona pellucida or undergo acrosomal exocytosis, even when a calcium signal is provided artificially in the form of the ionophore, A23187 (Williams et al., 1991; Yeung et al., 1996, 1997; Sirivaidyapong et al., 2001). These immature sperm are also incapable of the cAMP-dependent tyrosine phosphorylation cascade that characterizes capacitation (White and 
Aitken, 1989), thereby demonstrating that, at least in some species, sperm have to reach a certain stage of maturation before they can respond to $\mathrm{Ca}^{2+}$-influx and undergo the acrosome reaction; in the majority of species, sperm do not acquire fertilizing potential until they reach at least the mid-corpus (Dacheux and Paquignon, 1980).

In horses, sperm from the caput and corpus epididymides are almost completely unable to undergo the acrosome reaction in response to progesterone or calcium ionophore (unpublished data). More surprisingly, only a small proportion of sperm recovered from the cauda epididymides can undergo the acrosome reaction in response to progesterone $(6.25 \%)$, calcium ionophore $(13 \%)$ or a cAMP analogue (15\%). One possible explanation for this marked difference to other species (Sirivaidyapong et al., 2001) is the apparent failure of stallion sperm from the cauda epididymis to exhibit membrane progesterone receptors (Cheng et al., 1998). However, because neither cauda epididymal nor ejaculated sperm are capable of protein synthesis, it seems very unlikely that the receptor is de novo generated during or after ejaculation, and much more likely that the receptor is rendered temporarily non-functional or 'hidden' by some coating molecule secreted within the epididymis. While some sperm from the cauda epididymis did undergo the acrosome reaction $(6.25 \%)$, the amount was much less than that recorded for ejaculated sperm incubated identically (approximately 43\%: Rathi et al., 2003). Of course, the main difference between cauda epididymal and ejaculated sperm is exposure to seminal plasma during ejaculation, and it has been proposed that seminal plasma contains sperm 'activation' factors that release sperm from a quiescent state induced for epididymal storage. In principal, it should be easy to prove or disprove this hypothesis by incubating sperm from the cauda epididymis in seminal plasma prior to incubation in conditions designed to induce capacitation (bicarbonate) or the acrosome reaction (progesterone, calcium ionophore, cAMP). A recent preliminary study in our laboratory suggests that incubating sperm from the cauda epididymis with seminal plasma does indeed result in an increase in the proportion of sperm able to capacitate and undergo the acrosome reaction (unpublished data).

\subsection{Prostasomes}

Just like epididymal fluids, seminal plasma contains vesicular structures. In men and stallions, the vesicular fraction is believed to consist primarily of prostasomes, ranging in diameter from 130 to $180 \mathrm{~nm}$ (Ronquist and Brody, 1985; Arienti et al., 1998a). In men, these vesicles are thought to be produced by prostatic epithelial cells, in which they accumulate in so-called storage vesicles that resemble multivesicular bodies (Llorente et al., 2004; Sahlen et al., 2002). After exocytosis into the prostatic lumen, the prostasomes mix with the ejaculate.

The single membrane surrounding a prostasome is richer in cholesterol, sphingomyelin and saturated fatty acids than a normal somatic cell plasma membrane (Arienti et al., 1998b), and proteomic analysis of human prostasomes has yielded 139 proteins (Utleg et al., 2003). Although none of these proteins is truly specific for prostasomes, $34 \%$ are enzymes and the activity of prostasomic enzymes, such as dipeptidyl peptidase IV (DPP IV, CD26), is now often used to identify prostasomes (Belezza et al., 2005).

Although the exact function(s) of prostasomes is not known, several reproductive roles have been proposed (Burden et al., 2006), including the enhancement of sperm motility (Arienti et al., 1997). Prostasomes have also been reported to either prevent the sperm acrosome from becoming responsive to progesterone, via the greater cholesterol content (Cross and Mahasreshti, 1997), or conversely to stimulate the acrosome reaction when sperm and prostasomes are mixed at $\mathrm{pH}$ 5.5 (Palmerini et al., 2003). However, while a pH of 5.5 appears to promote sperm-prostasome fusion, the latter observation is questionable because a $\mathrm{pH}$ of 5.5 is not physiological. Prostasomes 
may also indirectly affect fertilization, for example by protecting sperm from immune cell attack within the female reproductive tract. In this respect, several inhibitors of the complement pathway are found on prostasomes and could prevent complement mediated lysis of sperm (Babiker et al., 2002; Kitamura et al., 1995). Some of these complement regulatory proteins (e.g. CD55 and CD59) are GPI-anchored (Rooney et al., 1996) and could, therefore, be transferred to the sperm cell surface by a mechanism similar to that proposed for epididymosomes. In addition, prostasomes inhibit lymphocyte proliferation (Kelly et al., 1991) and modulate neutrophil and monocyte phagocytosis (Skibinski et al., 1992). Finally, prostasomes have been described to exhibit antibacterial, antioxidant and virus neutralizing activities (Kitamura et al., 1995; Andersson et al., 2002; Saez et al., 1998). We have recently isolated and characterized prostasomes from stallion seminal plasma with the aim of studying their effects on sperm activation and recognition by immune cells.

\section{Conclusion}

In most mammalian species, maturation of sperm in the epididymis is an essential step in the development of progressive motility and fertilizing capacity. This maturation appears to result from modification of the sperm plasma membrane and flagellum induced by the ionic environment and/or the presence or absence of specific macromolecules within the epididymal lumen. Epididymal secretion induced remodelling of the sperm plasma membrane proteome almost certainly plays a major role in this maturation process.

Both epididymal and seminal fluids and membranous vesicles have been postulated to inhibit sperm capacitation via de-capacitation factors that coat the sperm surface and prevent the sperm from responding appropriately to capacitating stimuli. During in vitro fertilization (IVF), sperm are washed through a discontinuous density gradient and placed in a defined oviduct-like medium in an attempt to mimic the removal of de-capacitation factors that must occur in the female reproductive tract to enable fertilization. However, as this review should clarify, the actual process of sperm preparation for fertilization is probably much more complicated because: (i) Epididymal factors appear to be essential for sperm-zona binding, while (non-epididymal) seminal plasma factors also influence fertility; (ii) Other factors or vesicles present in epididymal and seminal fluids inhibit capacitation and stabilise the sperm membranes to protect them during storage and prevent premature activation during physiological transport. In summary, epididymal and accessory gland fluids have poorly understood but intriguing and complex functions in optimizing male fertility. Future studies should aim to determine the role of specific epididymal or accessory gland components in the maturation and activation of stallion sperm and to clarify the role of apocrine secreted vesicles such as epididymosomes and prostasomes on sperm maturation and function.

\section{Conflict of interest}

None.

\section{References}

Andersson, E., Sorensen, O.E., Frohm, B., Borregaard, N., Egesten, A., Malm, J., 2002. Isolation of human cationic antimicrobial protein-18 from seminal plasma and its association with prostasomes. Hum. Reprod. 17, $2529-2534$. 
Arienti, G., Carlini, E., Palmerini, C.A., 1997. Fusion of human sperm to prostasomes at acidic pH. J. Membr. Biol. 155, 89-94.

Arienti, G., Carlini, E., De Cosmo, A.M., Di Profio, P., Palmerini, C.A., 1998a. Prostasome-like particles in stallion semen. Biol. Reprod. 59, 309-313.

Arienti, G., Carlini, E., Polci, A., Cosmi, E.V., Palmerini, C.A., 1998b. Fatty acid pattern of human prostasome lipid. Arch. Biochem. Biophys. 358, 391-395.

Babiker, A.A., Ronquist, G., Nilsson, U.R., Nilsson, B., 2002. Transfer of prostasomal CD59 to CD59-deficient red blood cells results in protection against complement-mediated hemolysis. Am. J. Reprod. Immunol. 47, 183-192.

Barker, C.A., Gandier, J.C., 1957. Pregnancy in a mare resulting from frozen epididymal spermatozoa. Can. J. Comp. Med. Vet. Sci. 21, 47-51.

Bedford, J.M., 1965. Changes in fine structure of the rabbit sperm head during passage through the epididymis. J. Anat. 99, 891-906.

Bedford, J.M., Nicander, L., 1971. Ultrastructural changes in the acrosome and sperm membranes during maturation of spermatozoa in the testis and epididymis of the rabbit and monkey. J. Anat. 108, 527-543.

Belezza, I., Aisa, M.C., Palazzo, R., Costanzi, E., Mearini, E., Minelli, A., 2005. Extracellular matrix degrading enzymes at the prostasome surface. Prostate. Cancer. Prostatic. Dis. 8, 344-348.

Bérubé, B., Sullivan, R., 1994. Inhibition of in vivo fertilization by active immunization of male hamsters against a 26-kDa sperm glycoprotein. Biol. Reprod. 51, 1255-1263.

Bilinska, B., Hejmej, A., Gancarczyk, M., Sadowska, J., 2005. Immunoexpression of androgen receptors in the reproductive tract of the stallion. Ann. N.Y. Acad. Sci. 1040, 227-229.

Boué, F., Blais, J., Sullivan, R., 1996. Surface localization of P34H an epididymal protein, during maturation, capacitation, and acrosome reaction of human spermatozoa. Biol. Reprod. 54, 1009-1017.

Burden, H.P., Holmes, C.H., Persad, R., Whittington, K., 2006. Prostasomes-their effects on human male reproduction and fertility. Hum. Reprod. Update 12, 283-292.

Chakrabarti, R., Kline, D., Lu, J., Orth, J., Pilder, S., Vijayaraghavan, S., 2007. Analysis of Ppp1cc-null mice suggests a role for PP1gamma2 in sperm morphogenesis. Biol. Reprod. 76, 992-1001.

Cheng, F.P., Gadella, B.M., Voorhout, W.F., Fazeli, A.R., Bevers, M.M., Colenbrande, R.B., 1998. Progesterone-induced acrosome reaction in stallion spermatozoa is mediated by a plasma membrane progesterone receptor. Biol. Reprod. 59, 733-742.

Cherr, G.N., Yudin, A.I., Overstreet, J.W., 2001. The dual functions of GPI-anchored PH-20: hyaluronidase and intracellular signaling. Matrix Biol. 20, 515-525.

Cross, N.L., Mahasreshti, P., 1997. Prostasome fraction of human seminal plasma prevents sperm from becoming acrosomally responsive to the agonist progesterone. Arch. Androl. 39, 39-44.

Dacheux, J.L., Paquignon, M., 1980. Relations between the fertilizing ability, motility and metabolism of epididymal spermatozoa. Reprod. Nutr. Dev. 20, 1085-1099.

Dacheux, J.L., Gatti, J.L., Dacheux, F., 2003. Contribution of epididymal secretory proteins for spermatozoa maturation. Microsc. Res. Tech. 61, 7-17.

Dias, G.M., Retamal, C.A., Tobella, L., Arnholdt, A.C., López, M.L., 2006. Nuclear status of immature and mature stallion spermatozoa. Theriogenology 66, 354-365.

Eickhoff, R., Baldauf, C., Koyro, H.W., Wennemuth, G., Suga, Y., Seitz, J., Henkel, R., Meinhardt, A., 2004. Influence of macrophage migration inhibitory factor (MIF) on the zinc content and redox state of protein-bound sulphydryl groups in rat sperm: indications for a new role of MIF in sperm maturation. Mol. Hum. Reprod. 10, 605-611.

Eickhoff, R., Jennemann, G., Hoffbauer, G., Schuring, M.P., Kaltner, H., Sinowatz, F., Gabius, H.J., Seitz, J., 2006. Immunohistochemical detection of macrophage migration inhibitory factor in fetal and adult bovine epididymis: release by the apocrine secretion mode? Cells Tissues Organs 182, 22-31.

Fouchécourt, S., Métayer, S., Locatelli, A., Dacheux, F., Dacheux, J.L., 2000. Stallion epididymal fluid proteome: qualitative and quantitative characterization; secretion and dynamic changes of major proteins. Biol. Reprod. 62, 1790-1803.

França, L., Avelar, G., Almeida, F., 2005. Spermatogenesis and sperm transit through the epididymis in mammals with emphasis on pigs. Theriogenology 63, 300-318.

Frenette, G., Sullivan, R., 2001. Prostasome-like particles are involved in the transfer of P25b from the bovine epididymal fluid to the sperm surface. Mol. Reprod Dev. 59, 115-121.

Frenette, G., Lessard, C., Sullivan, R., 2004. Polyol pathway along the bovine epididymis. Mol. Reprod. Dev. 69, $448-456$. Frenette, G., Légaré, C., Saez, F., Sullivan, R., 2005. Macrophage migration inhibitory factor in the human epididymis and semen. Mol. Hum. Reprod. 11, 575-582. 
Frenette, G., Girouard, J., Sullivan, R., 2006. Comparison between epididymosomes collected in the intraluminal compartment of the bovine caput and cauda epididymidis. Biol. Reprod. 75, 885-890.

Gatti, J.L., Castella, S., Dacheux, F., Ecroyd, H., Métayer, S., Thimon, V., Dacheux, J.L., 2004. Post-testicular sperm environment and fertility. Anim. Reprod. Sci. 82/83, 321-339.

Gaudreault, C., Lé garé, C., Bérubé, B., Sullivan, R., 1999. Hamster sperm protein, p26h: a member of the short-chain dehydrogenase/reductase superfamily. Biol. Reprod. 61, 264-273.

Hess, R.A., Bunick, D., Lee, K.H., Bahr, J., Taylor, J.A., Korach, K.S., Lubahn, D.B., 1997. A role for oestrogens in the male reproductive system. Nature 390, 509-512.

Jones, R.C., 1998a. Evolution of the vertebrate epididymis. J. Reprod. Fertil. Suppl. 53, 163-181.

Jones, R., 1998b. Plasma membrane structure and remodelling during sperm maturation in the epididymis. J. Reprod. Fertil. Suppl. 53, 73-84.

Jones, R., 2004. Sperm survival versus degradation in the Mammalian epididymis: a hypothesis. Biol. Reprod. 71, 1405-1411.

Jones, R., Glover, T.D., 1975. Interrelationships between spermatozoa, the epididymis and epididymal plasma. In: Duckett, J.G., Racey, P.A. (Eds.), The Biology of the Male Gamete, Biol. J. Linn. Soc; 7 (Suppl. 1), 367-384.

Jones, R., James, P.S., Howes, L., Bruckbauer, A., Klenerman, D., 2007. Supramolecular organization of the sperm plasma membrane during maturation and capacitation. Asian. J. Androl. 9, 438-444.

Kelly, R.W., Holland, P., Skibinski, G., Harrison, C., McMillan, L., Hargreave, T., James, K., 1991. Extracellular organelles (prostasomes) are immunosuppressive components of human semen. Clin. Exp. Immunol. 86, 550-556.

Kirchhoff, C., 1996. CD52 is the 'major maturation-associated' sperm membrane antigen. Mol. Hum. Reprod. 2, 9-17.

Kitamura, M., Namiki, M., Matsumiya, K., Tanaka, K., Matsumoto, M., Hara, T., Kiyohara, H., Okabe, M., Okuyama, A., Seya, T., 1995. Membrane cofactor protein (CD46) in seminal plasma is a prostasome-bound form with complement regulatory activity and measles virus neutralizing activity. Immunology 84, 626-632.

Krull, N., Ivell, R., Osterhoff, C., Kirchhoff, C., 1993. Region-specific variation of gene expression in the human epididymis as revealed by in situ hybridization with tissue-specific cDNAs. Mol. Reprod. Dev. 34, 16-24.

Lamontagne, N., Légaré, C., Gaudreault, C., Sullivan, R., 2001. Identification and characterization of P31m, a novel sperm protein in Cynomolgus monkey (Macaca fascicularis). Mol. Reprod. Dev. 59, 431-441.

Llorente, A., de Marco, M.C., Alonso, M.A., 2004. Caveolin-1 and MAL are located on prostasomes secreted by the prostate cancer PC-3 cell line. J. Cell. Sci. 117, 5343-5351.

López, M.L., Olea, N., Retamal, C.A., 2007. Post-testicular changes in the density and distribution of intramembrane particles of stallion sperm surface domains. Anim. Reprod. Sci. 100, 204-210.

Moore, H.D.M., 1995. Post-testicular sperm maturation and transport in the excurrent duct. In: Grudzinskas, J.G., Yovich, J.L. (Eds.), Gametes-The Spermatozoon. Cambridge University Press, pp. 140-157.

Morris, L.H., 2004. Low dose insemination in the mare: an update. Anim. Reprod. Sci. 82/83, 625-632.

Morris, L.H.A., Tiplady, C.A., Wilsher, S., Allen, W.R., 2000. Hysteroscopic uterotubal insemination of mares with low number of frozen-thawed ejaculated and epididymal spermatozoa. In: Proceedings of the 5th International Symposium on Equine embryo transfer, Saari, Finland, pp. 4-5.

Nickel, R.A., Schummer, A., Seiferle, E., 1979. Male genital organs. In: The Viscera of the Domestic Mammals, 2 nd ed. Verslag Paul Parey, Berlin, p. 304.

Olson, G.E., Winfrey, V.P., Nagdas, S.K., 2003. Structural modification of the hamster sperm acrosome during posttesticular development in the epididymis. Microsc. Res. Tech. 61, 46-55.

Palmerini, C.A., Saccardi, C., Carlini, E., Fabiani, R., Arienti, G., 2003. Fusion of prostasomes to human spermatozoa stimulates the acrosome reaction. Fertil. Steril. 80, 1181-1184.

Parent, S., Lefièvre, L., Brindle, Y., Sullivan, R., 1999. Bull subfertility is associated with low levels of a sperm membrane antigen. Mol. Reprod. Dev. 52, 57-65.

Parlevliet, J.M., Pearl, C.A., Hess, M.F., Famula, T.R., Roser, J.F., 2006. Immunolocalization of estrogen and androgen receptors and steroid concentrations in the stallion epididymis. Theriogenology 66, 755-765.

Rathi, R., Colenbrander, B., Stout, T.A., Bevers, M.M., Gadella, B.M., 2003. Progesterone induces acrosome reaction in stallion spermatozoa via a protein tyrosine kinase dependent pathway. Mol. Reprod. Dev. 64, 120-128.

Rejraji, H., Sion, B., Prensier, G., Carreras, M., Motta, C., Frenoux, J.M., Vericel, E., Grizard, G., Vernet, P., Drevet, J.R., 2006. Lipid remodeling of murine epididymosomes and spermatozoa during epididymal maturation. Biol. Reprod. 74, 1104-1113.

Retamal, C., Urzúa, J., Lorca, C., López, M.L., Alves, E.W., 2000. Changes in the plasma membrane proteins of stallion spermatozoa during maturation in the epididymis. J. Submicrosc. Cytol. Pathol. 32, 229-239. 
Reyes-Moreno, C., Laflamme, J., Frenette, G., Sirard, M.A., Sullivan, R., 2008. Spermatozoa modulate epididymal cell proliferation and protein secretion in vitro. Mol. Reprod. Dev. 75, 512-520.

Robaire, B., Viger, R., 1995. Regulation of epididymal epithelial cell functions. Biol. Reprod. 52, $226-236$.

Robitaille, G., Sullivan, R., Bleau, G., 1991. Identification of epididymal proteins associated with hamster sperm. J. Exp. Zool. 258, 69-74.

Ronquist, G., Brody, I., 1985. The prostasome: its secretion and function in man. Biochim. Biophys. Acta. 822, $203-218$.

Rooney, I.A., Heuser, J.E., Atkinson, J.P., 1996. GPI-anchored complement regulatory proteins in seminal plasma. An analysis of their physical condition and the mechanisms of their binding to exogenous cells. J. Clin. Invest. 97, 1675-1686.

Saether, T., Tran, T.N., Rootwelt, H., Christophersen, B.O., Haugen, T.B., 2003. Expression and regulation of delta5desaturase, delta6-desaturase, stearoyl-coenzyme A (CoA) desaturase 1, and stearoyl-CoA desaturase 2 in rat testis. Biol. Reprod. 69, 117-124.

Saez, F., Motta, C., Boucher, D., Grizard, G., 1998. Antioxidant capacity of prostasomes in human semen. Mol. Hum. Reprod. 4, 667-672.

Sahlen, G.E., Egevad, L., Ahlander, A., Norlen, B.J., Ronquist, G., Nilsson, B.O., 2002. Ultrastructure of the secretion of prostasomes from benign and malignant epithelial cells in the prostate. Prostate 53, 192-199.

Seligman, J., Zipser, Y., Kosower, N.S., 2004. Tyrosine phosphorylation, thiol status and protein tyrosine phosphatase in rat epididymal spermatozoa. Biol. Reprod. 71, 1009-1015.

Sirivaidyapong, S., Bevers, M.M., Gadella, B.M., Colenbrander, B., 2001. Induction of the acrosome reaction in dog sperm cells is dependant on epididymal maturation: the generation of a functional progesterone receptor is involved. Mol. Reprod. Dev. 58, 451-459.

Skibinski, G., Kelly, R.W., Harkiss, D., James, K., 1992. Immunosuppression by human seminal plasma-extracellular organelles (prostasomes) modulate activity of phagocytic cells. Am. J. Reprod. Immunol. 28, 97-103.

Sullivan, R., Saez, F., Girouard, J., Frenette, G., 2005. Role of exosomes in sperm maturation during the transit along the male reproductive tract. Blood. Cells. Mol. Dis. 35, 1-10.

Sullivan, R., Frenette, G., Girouard, J., 2007. Epididymosomes are involved in the acquisition of new sperm proteins during epididymal transit. Asian. J. Androl. 9, 483-491.

Tash, J.S., Bracho, G.E., 1994. Regulation of sperm motility: emerging evidence for a major role for protein phosphatases. J. Androl. 15, 505-509.

Utleg, A.G., Yi, E.C., Xie, T., Shannon, P., White, J.T., Goodlett, D.R., Hood, L., Lin, B., 2003. Proteomic analysis of human prostasomes. Prostate 56, 150-161.

Vijayaraghavan, S., Chakrabarti, R., Myers, K., 2007. Regulation of sperm function by protein phosphatase PP1gamma2. Soc. Reprod. Fertil. Suppl. 63, 111-121.

White, D.R., Aitken, R.J., 1989. Influence of epididymal maturation on cyclic AMP levels in hamster spermatozoa. Int. J. Androl. 12, 29-43.

Williams, R.M., Graham, J.K., Hammerstedt, R.H., 1991. Determination of the capacity of ram epididymal and ejaculated sperm to undergo the acrosome reaction and penetrate ova. Biol. Reprod. 44, 1080-1091.

Yanagimachi, R., 1994. Mammalian fertilization. In: Knobil, E., Neill, J.D. (Eds.), The Phisiology of Reproduction. Raven Press, Ltd., New York, pp. 189-317.

Yeung, C.H., Cooper, T.G., Weinbauer, G.F., 1996. Maturation of monkey spermatozoa in the epididymis with respect to their ability to undergo the acrosome reaction. J. Androl. 17, 427-432.

Yeung, C.H., Perez-Sanchez, F., Soler, C., Poser, D., Kliesch, S., Cooper, T.G., 1997. Maturation of human spermatozoa (from selected epididymides of prostatic carcinoma patients) with respect to their morphology and ability to undergo the acrosome reaction. Hum. Reprod. Update 3, 205-213.

Yeung, C.H., Pérez-Sánchez, F., Schröter, S., Kirchhoff, C., Cooper, T.G., 2001. Changes of the major sperm maturationassociated epididymal protein HE5 (CD52) on human ejaculated spermatozoa during incubation. Mol. Hum. Reprod. 7, 617-624.

Yoshinaga, K., Toshimori, K., 2003. Organization and modifications of sperm acrosomal molecules during spermatogenesis and epididymal maturation. Microsc. Res. Tech. 61, 39-45.

Zhang, H., Jones, R., Martin-DeLeon, P.A., 2004. Expression and secretion of rat SPAM1(2B1 or PH-20) in the epididymis: role of testicular lumicrine factors. Matrix. Biol. 22, 653-661. 